\title{
A systematic review of protocol studies on conceptual design cognition
}

\author{
Laura Hay, Chris McTeague, Alex H. B. Duffy, Laura M. Pidgeon, \\ Tijana Vuletic, Madeleine Grealy \\ University of Strathclyde
}

This paper reports the first systematic review and synthesis of protocol studies on conceptual design cognition. 47 studies from the domains of architectural design, engineering design, and product design engineering were reviewed towards answering the following question: What is our current understanding of the cognitive processes involved in conceptual design tasks carried out by individual designers? Studies were found to reflect three viewpoints on the cognitive nature of designing: design as search; design as exploration; and design activities. Synthesising the findings of individual studies revealed ten categories of executive and nonexecutive function studied across the viewpoints: visual perception; mental imagery; semantic association; long term memory; working memory; selective attention; creative thinking; evaluation and decision making; externalisation; and reasoning and problem solving. The review highlights several avenues for future research, centering on the need for general formalisms, more objective methods to supplement protocol analysis, and a shared ontology of cognitive processes.

\section{Introduction}

Conceptual design refers to the early stages of the design process, where design requirements and solutions may be fuzzy, unstructured, and/or illdefined $[1,2]$. Generating a high number of ideas during conceptual design is believed to increase the likelihood of achieving a desirable product in terms of cost and quality [3]. Thus, conceptual design may have a significant impact upon design performance later in the design process. However, 
there is a lack of clarity regarding the nature of the cognitive processes involved in this influential phase of designing. Jin and Benami [3] note that whilst cognitive processes "are at the center in developing new ideas, they are rarely taken into account in research and development of design support methods and systems" (p.191). In a more recent study, Kim and Ryu [4] claim that conceptual design involves "perception, problem solving, reasoning, and thinking about the design." Nonetheless, they argue that there is a need for thorough research "to better understand designers' internal cognitive processes" (p.519). More generally, Dorst and Cross [5] note that the internal mechanisms involved in creative idea generation are "mysterious (and often mystified)" (p.425).

\section{The systematic review method}

A plethora of empirical studies have been conducted on conceptual design cognition since the late 1970s, contributing a wealth of observations on different aspects of cognition and the factors affecting it in the early stages of design [6,7]. However, there has thus far been only a single attempt to systematically review and synthesise the findings from these studies [8]. This review focused largely on methodological aspects of protocol analysis; a similar exercise could provide greater clarity on the cognitive processes involved in conceptual design. Whilst Cross [6] and Dinar et al. [7] provide detailed and instructive treatments of empricial studies on design cognition, their reviews are broader in scope and cannot be considered to be systematic in nature. The systematic literature review is a research method whereby every quality publication on a particular topic is gathered and synthesised through a rigorous and transparent process. The intention is that all valid and reliable evidence relating to a particular phenomenon is considered by the researcher, minimising the potential for bias. Adherence to guidelines for conducting and reporting systematic reviews (e.g. the PRISMA guidelines [9]) ensures that a systematic literature review is fully reproducible, and therefore meets the same standards typically applied to empirical research. Consequently, systematic reviews can provide a foundation for the development of formal theories and models of conceptual design cognition.

To address the need for greater clarity on the nature of the cognitive processes involved in conceptual design, this paper presents the findings of the first systematic review of protocol studies specifically focusing on conceptual design cognition. Studies from the domains of architectural design, engineering design, and product design engineering were considered. The review aimed to answer the following research question by synthesising the findings of individual studies: What is our current understanding of 
the cognitive processes involved in conceptual design tasks carried out by individual designers? We focused on protocol studies because unlike other empirical methods, protocol analysis is generally considered to provide direct access to a designer's cognitive processes $[7,10]$. Consequently, Cross [6] notes that the method "has become regarded as the most likely method (perhaps the only method) to bring out into the open the somewhat mysterious cognitive abilities of designers" (p.80).

\section{Methods}

Our approach was informed by the PRISMA guidelines for systematic reviews [9]. The review was conducted by two researchers with a background in product design engineering, with input from a cognitive neuroscience researcher where required.

\section{Review scope}

As stated previously, the review focused on the conceptual design phase of the design process. Only studies focusing on design tasks carried out by individual designers were included; studies examining group-based tasks were not considered. Studies from three design domains were included in the sample:

- Engineering design, i.e. the design of technical products, with a primary focus on relatively complex functional requirements [11].

- Product design engineering, i.e. the design of products involving a combination of functional requirements and requirements for aspects such as form, aesthetics, usability, ergonomics, and marketing/branding issues $[12,13]$.

- Architectural design, i.e. the design of buildings, their interiors, and their surroundings. Like product design engineering, architectural design may involve a combination of functional and nonfunctional requirements [14].

Findings from studies originating in these domains are argued to be comparable, and therefore conducive to synthesis, on the basis that they adopt similar: (i) views on the nature of designing, i.e. designing is generally considered to involve identifying a function to meet a need, developing behaviours to fulfil the function, and synthesising structures to exhibit the behaviours [15]; and (ii) paradigms for describing design cognition, i.e. the problem solving and reflective paradigms as discussed by [16]. 


\section{Search strategy and article selection process}

A flowchart outlining the article selection process and the number of articles included/rejected at each stage is presented in Figure 1. Literature was initially gathered through searches of major engineering and psychology databases (e.g. Compendex, Technology Research Database, and PsycINFO) conducted between $27^{\text {th }}$ March 2015 and $3^{\text {rd }}$ April 2015. Search terms are presented in Figure 2. Following removal of duplicate articles, a range of study types were identified within the corpus e.g. controlled experiments, protocol studies, case studies, and surveys. It was decided to focus the review on protocol studies for reasons stated in the introduction. These underwent eligibility assessment against six inclusion criteria (Table 1); the reference lists of included articles were then manually searched to identify further candidates for inclusion. Additional candidates were also identified from follow-up database searches using terms reflecting the protocol analysis method (run on $9^{\text {th }}$ October 2015). All candidates for inclusion underwent eligibility assessment against the criteria in Table 1. Note that conference papers published prior to 2005 were excluded on the basis that they largely constituted early versions of research that was later re-published and updated in a journal article, e.g. [17-19]. Eligible articles from initial database searches, reference list searches, and follow-up database searches were then consolidated to produce a final set of 47 articles for inclusion in the review.

Table 1 Inclusion criteria

\begin{tabular}{l|l}
\hline No. & Criterion \\
\hline 1 & Article must be published in English. \\
\hline 2 & $\begin{array}{l}\text { If constituting a conference paper, article must be published during or after } \\
2005 .\end{array}$ \\
\hline 3 & Article must report original research. \\
\hline 4 & Study participants must be individual designers, i.e. not pairs or groups. \\
\hline 5 & $\begin{array}{l}\text { Study participants must carry out a conceptual design task within the do- } \\
\text { mains of engineering design, product design engineering, or architectural } \\
\text { design. }\end{array}$ \\
\hline 6 & $\begin{array}{l}\text { Authors must identify cognitive processes involved in a conceptual design } \\
\text { task. }\end{array}$ \\
\hline
\end{tabular}




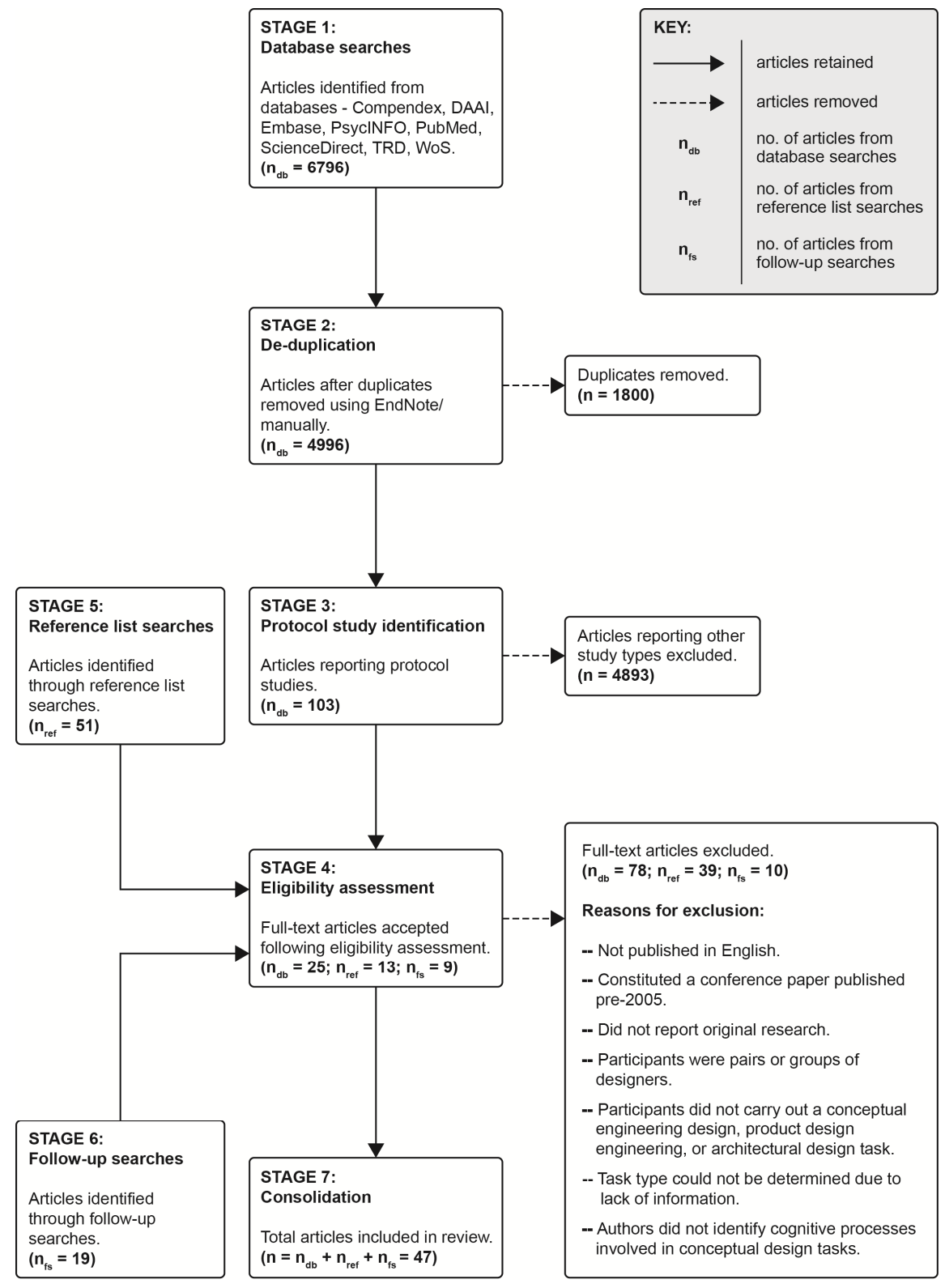

Fig1. Article selection process (adapted from [9]) 


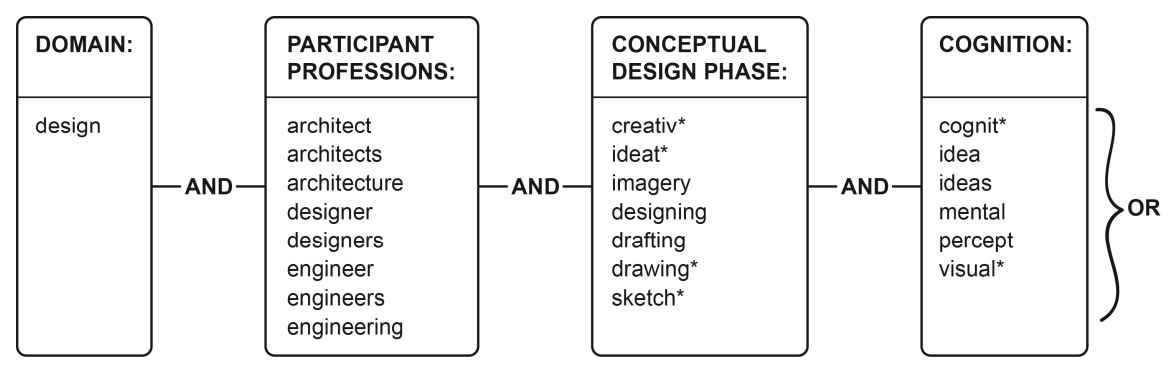

Fig2. Search terms and search structure

\section{Characteristics of reviewed studies}

Studies included in the review are denoted with * in the reference list at the end of this paper. Owing to space limitations, it was not possible to include the full sample in this paper. Key characteristics of the studies may be summarised as follows:

- The oldest study was published in 1984 [20], and the newest in 2015 e.g. [21]. $53.2 \%$ of studies were published in the last 10 years.

- $76.6 \%$ of the articles reported full protocol studies, and $23.4 \%$ reported analyses of existing protocol data.

- Studies involved a total of approximately 350 participants, ranging from a minimum of 1 to a maximum of 36 participants per study and an average of 7 participants. Participants included practicing designers and architects, along with students at undergraduate, Master's, and $\mathrm{PhD}$ level.

- The experience levels of participants ranged from 0 to 38 years, although authors were observed to apply inconsistent definitions of "experience."

- 45 distinct design tasks were studied $-44.4 \%$ architectural design, $42.2 \%$ product design engineering, and $13.3 \%$ engineering design.

- The following types of data were gathered by authors: concurrent verbalisations during tasks $(68.1 \%)$; retrospective verbalisations after tasks $(23.4 \%)$; combined current and retrospective verbalisations $(8.5 \%)$; video of designer behaviour $(84.4 \%)$; and physical sketches $(51.1 \%)$.

- The length of verbal protocols ranged from 15 to 600 minutes. 


\section{Focus of reviewed studies}

Collectively, studies were found to reflect three viewpoints on the cognitive nature of designing: (V1) design as search; (V2) design as exploration; and (V3) design activities. A range of focus areas were then identified from studies associated with each viewpoint, as summarised in the subsections below. Note that the research question is answered later in the paper.

\section{Viewpoint 1: design as search}

The first viewpoint reflected in the studies considers designing to constitute a goal-directed search process. Central to this viewpoint is the perspective that a designer may be modelled as an information processing system (IPS) [22,23]. As an IPS, a designer transforms information from input to output states via the execution of elementary information processes known as operators [23]. These transformations may be termed state transformations $[2,20]$.

Stauffer and Ullman [23] suggest that during designing, the processor component of the IPS "accesses information from the LTM [long term memory] into the STM [short term memory, i.e. working memory] as it is needed by the operators" (p.117). Operators then act on the retrieved information in working memory to effect a transformation of the design state, which is proposed to be manifested initially as changes in the information content of working memory. Drawing from the work of Newell and Simon [24], Chan [22] highlights that the sequence of operators and state transformations involved in conceptual design may be formalised as "a search through [...] knowledge states" (p.64) i.e. a search process. Studies on design as search were found to reflect three focus areas, which are briefly summarised below.

Search processes and their context in problem spaces. Search processes are considered to be bounded by a problem space. The problem space encompasses knowledge of the initial problem state, a goal state, and all possible design states in between these two states. Design as search may then be viewed as a sequence of state transformations, beginning with the problem state and proceeding through intermediate design states until the goal state is reached [2,22-24]. Transformations may be (i) lateral, i.e. generation of a new solution, or (ii) vertical, i.e. elaboration of a current solution [2]. Design problem spaces are typically large owing to the illdefined nature of design problems; however, a designer may reduce the size of the space to be searched by implementing constraints [2,22]. Search 
processes are further managed with design goals specifing desired design states [22,23].

Search methods, control strategies, and knowledge schema. Operators may be applied in different combinations and sequences to reach a solution and manage the search process. These patterns of operator execution are described as search methods [23] and control strategies [22], respectively. Owing to the necessary space limitations of a conference paper, the full range of search methods, control strategies, and operators identified from the reviewed studies cannot be presented here. Chan [22] proposes that operators are retrieved from knowledge schema stored in long term memory. That is, networks of knowledge units encapsulating both declarative and procedural knowledge [22,25].

Problem solving phases. Several authors were observed to delimit designing into problem structuring and problem solving (or search) phases. Akin [20] suggests that designers structure the problem during a presketching phase, and solve it during a "search for design" phase (p.204). Similarly, Goel [2] argues that problem structuring may occur at the start of design tasks; however, it may also "recur periodically as needed" (p.114). This is supported by Chan [22], who suggests that problems may be restructured during tasks in response to a "critical problem situation" (p.69), e.g. a decision to abandon a solution.

\section{Viewpoint 2: design as exploration}

A second viewpoint reflected in the studies considers designing to constitute an exploratory process operating between problem and solution spaces. Central to this viewpoint is the perspective that design problems are evolutionary in nature -i.e. they may be reinterpreted and reformulated as designing progresses and a solution is developed [26,27].

When design problems are viewed as evolutionary, the designer's task environment may be subdivided into (i) a problem space, encompassing knowledge of design requirements; and (ii) a solution space, encompassing knowledge of design solutions [26]. Rather than a search process, design may then be viewed as an exploratory process operating within and between these two spaces, where actions taken in the solution space (e.g. idea generation or concept development) may influence actions taken in the problem space (e.g. problem structuring or reformulation) and vice versa [5]. Interactions between the two spaces may also be understood in terms of the concept of situatedness, e.g. the notion that a designer's understanding of a problem is affected by what they draw and perceive in their sketches, and vice versa [28]. 
Studies on design as exploration were found to reflect two broad focus areas, namely co-evolutionary design and sketch-based design exploration. Sketch-based exploration may be further subdivided into the following areas: visual reasoning; cognitive actions; and unexpected discoveries and situated invention. Each area is briefly summarised in the following paragraphs.

Co-evolutionary design. The co-evolution model proposed by Maher et al. 1996 (cited in [5]) formalises the problem and solution spaces outlined above. Designing is described as a co-evolutionary process - that is, according to Maher and Tang [26], a process that "explores the spaces of problem requirements and design solutions iteratively" (p.48), resulting in the evolution of design problems alongside solutions. The solution space provides the basis to evaluate/re-evaluate requirements in the problem space, and the problem space facilitates evalution of solutions proposed in the solution space. Interactions between the two spaces "may add new variables into both" (p.48), e.g. new design requirements in the problem space or potential solutions in the solution space. That is, the interactions may change the focus of designing.

Visual reasoning. Goldschmidt [29] proposes that during sketch-based design tasks, designers follow a pattern of "dialectical reasoning" about the visual features of the sketch in relation to the design problem (p.139). That is, a pattern of visual reasoning that continually shifts between two modes: (i) seeing as, i.e. proposing properties/attributes that a design could possess based on e.g. metaphors and analogies; and (ii) seeing that, i.e. developing a rationale for design decisions relating to these proposals. Park and Kim [30] model visual reasoning in terms of three interrelated cognitive activities: (i) seeing, i.e. the perception, analysis, and interpretation of visual information in external representations; (ii) imagining, i.e. the synthesis of perceptual and conceptual information produced by seeing in order to generate and transform new internal representations; and (iii) drawing, i.e. the evaluation, confirmation, and externalisation of internal representations.

Cognitive actions. Suwa et al. [31] propose a set of "cognitive actions" intended to comprehensively capture a designer's cognition during sketching tasks. These are organised into physical, perceptual, functional, and conceptual categories. The categories are partly based on the work of Suwa and Tversky [32], and are argued to "correspond to the levels at which incoming information is thought to be processed in human cognition" (p.459). That is, sensorily (physical actions), then perceptually (perceptual actions), and finally semantically (functional and conceptual actions). Suwa et al. [31] claim that the proposed actions are supported by "an enormous amount of concrete examples" (p.458) identified from the protocol of an architect studied by [32]. 
Unexpected discoveries and situated requirements invention. Suwa et al. [28] propose that during sketching tasks, designers may unintentionally create spatial relations between elements. Visuo-spatial features created by these relations may then be "discovered in an unexpected way" later in the design task (p.540). Suwa et al. [28] found that unexpected discoveries are often followed by cognitive actions to set up goals focusing on new issues, which in certain cases "become general enough to be carried through the entire design process as one of the primary design requirements" (p.547). This is termed "situated-invention" by the authors (p.540). Unexpected discoveries and situated invention were observed to be correlated bidirectionally, i.e. unexpected discoveries appear to drive situated invention and vice versa over the course of a sketch-based design task.

Finally, it should be noted that a number of authors have also examined the role and significance of sketching in conceptual design, e.g. [33-36]. Whilst several of these studies conclude that sketches act as a form of 'external memory' that serves to offload a designer's visuo-spatial working memory $[33,35]$, the majority also demonstrate that designing using mental imagery alone may still result in satisfactory design outcomes.

\section{Viewpoint 3: design activities}

The final viewpoint reflected in the studies considers designing to constitute a cognitive activity that may be decomposed into sub-activities that occur in particular patterns [11,37]. In this respect, a number of authors in the broader design literature may be seen to outline classifications of design activities, e.g. Hubka [11] formulates a hierarchy of design activities occurring at different points in the design process, and Sim and Duffy [38] propose an ontology of design activities organised into different categories.

Four major design activities associated with conceptual design were found to be studied by authors in the sample, namely: problem analysis; concept generation and synthesis; and evaluation. The nature of each activity is briefly outlined below. Authors were observed to study the activities both individually [39] and as part of studies on cognitive models [27] and activity patterns during the design process [1].

Problem analysis. Problem analysis involves understanding the design problem, setting goals, and defining constraints and requirements [27]. Authors were found to highlight a number of sub-activities involved in problem analysis, namely: information gathering [40]; inference [41,42]; problem decomposition $[2,39,42,43]$; identifying, exploring, clarifying, and prioritising constraints and requirements $[40,44,45]$; and problem reframing [46]. 
Concept generation and synthesis. Concept generation may be positioned as involving the generation of ideas or partial solutions, and the synthesis of these into more mature or complete concepts [27]. However, in certain studies, idea generation and synthesis are treated as separate activities $[27,47]$. In addition to synthesis, authors were found to highlight further sub-activities involved in concept generation, namely: memory retrieval $[3,44] ;$ association/analogical reasoning/case-based reasoning $[3,21,25,45,48]$; and the generation/transformation/ maintenance of internal representations $[3,30,44]$.

Evaluation. Evaluation entails the assessment of concepts against design requirements, constraints, and criteria [27] typically defined during problem analysis [47]. Authors were found to highlight the following as sub-activities involved in evaluation: comparing $[4,41]$; judging, on the basis of value [41,47], aesthetics [49], affect [4], or objective criteria $[43,47,48]$; and decision making with respect to which concept should be taken forward from a range of alternatives $[43,47,48]$.

\section{Cognitive processes in conceptual design}

As discussed in the introduction, the systematic review reported herein aimed to address the following question by synthesising the findings of individual protocol studies conducted to date: What is our current understanding of the cognitive processes involved in conceptual design tasks carried out by individual designers? Having summarised the characteristics and focus of the reviewed studies, the following sub-sections provide answers to the research question and briefly discuss future work and challenges for the field.

\section{Processes identified from protocol studies}

To answer the research question, we firstly identified specific cognitive processes observed and discussed by authors in the focus areas reviewed previously. This revealed considerable differences in the concepts and terminology used to describe cognition. For instance, studies on design as search tend to use the language of problem solving research, describing cognition in terms of operators and state transformations [20,22,30]. In constrast, studies on design as exploration frequently describe cognition in terms of perception and the notion of situatedness [28,30]. To some extent, these differences may be considered to derive from differences in the paradigms underlying each viewpoint. For example, it may be seen from the previous section that studies on design as search largely align with the per- 
spectives of the problem solving paradigm (Table 2), founded in the work of Newell and Simon [24]. In contrast, studies on design as exploration typically align with the perspectives of the reflective paradigm (Table 2), drawing from the work of Schon [50]. Studies on design activities variously reflect perspectives from both paradigms, or neither.

Table 2 Key perspectives associated with the problem solving and reflective paradigms in design cognition research

\begin{tabular}{|c|c|c|c|c|}
\hline \multirow[b]{2}{*}{ Paradigms: } & \multicolumn{4}{|c|}{$\begin{array}{l}\text { Perspectives on the nature of: } \\
\text { (based on [16]) }\end{array}$} \\
\hline & Designer & $\begin{array}{l}\text { Design prob- } \\
\text { lem }\end{array}$ & Designing & $\begin{array}{l}\text { Design } \\
\text { knowledge }\end{array}$ \\
\hline $\begin{array}{l}\text { Problem } \\
\text { solving }\end{array}$ & $\begin{array}{l}\text { Information } \\
\text { processor in } \\
\text { an objective } \\
\text { reality. }\end{array}$ & $\begin{array}{l}\text { Ill-defined, } \\
\text { unstructured, } \\
\text { stable. }\end{array}$ & $\begin{array}{l}\text { A rational } \\
\text { search pro- } \\
\text { cess. }\end{array}$ & $\begin{array}{l}\text { Design proce- } \\
\text { dures and sci- } \\
\text { entific laws. }\end{array}$ \\
\hline $\begin{array}{l}\text { Reflective } \\
\text { practice }\end{array}$ & $\begin{array}{l}\text { Person con- } \\
\text { structing their } \\
\text { reality. }\end{array}$ & $\begin{array}{l}\text { Essentially } \\
\text { unique, evolu- } \\
\text { tionary. }\end{array}$ & $\begin{array}{l}\text { Reflective in- } \\
\text { teraction with } \\
\text { broader design } \\
\text { situation. }\end{array}$ & $\begin{array}{l}\text { When to apply } \\
\text { what proce- } \\
\text { dure or com- } \\
\text { ponent of } \\
\text { knowledge. }\end{array}$ \\
\hline
\end{tabular}

A major benefit of a systematic review is that it can reveal common findings across a large set of studies. However, owing to the differences in terminology and concepts discussed above, it is difficult to determine what cognitive processes are common across different viewpoints and therefore likely to be fundamentally involved in conceptual design tasks. To gain a clearer view in this respect, we grouped identified processes based on similarities conveyed in definitions and explanations, revealing 10 categories of cognitive function that appear to be studied across the different viewpoints and domains covered by the review: (1) visual perception; (2) mental imagery; (3) semantic association; (4) long term memory; (5) working memory; (6) selective attention; (7) creative thinking; (8) evaluation and decision making; (9) externalisation; and (10) reasoning and problem solving. A useful distinction that is often made in the study and classification of cognitive processes in psychololgy is that between executive and non-executive functions. Executive functions refer to cognitive processes involved in the selection and monitoring of behaviours to achieve goals, and are accessible to consciousness. In contrast, non-executive functions are typically subconscious, largely automatic processes such as perception and memory retrieval [51,52]. Processes $1-4$ above may be 
classed as non-executive functions, whilst $5-10$ constitute executive functions.

Each of the above functions is presented and defined in Table 3, alongside the particular cognitive processes identified through the review. Processes presented in column 2 are the outcome of generalising specific examples identified from the reviewed studies. Illustrative examples in this respect are presented in column 3. Owing to the space limitations of a conference paper, it is not possible to present every specific example identified. Note that the function categories were based on the set of identified processes, but informed by the cognitive psychology literature (as indicated by the citations in column 1).

Table 3 Identified processes and function categories

\begin{tabular}{|c|c|c|}
\hline Function category & Cog. processes & Specific examples \\
\hline \multirow{3}{*}{$\begin{array}{l}\text { Visual perception, i.e. the } \\
\text { process of constructing } \\
\text { and consciously sensing } \\
\text { internal (visual) represen- } \\
\text { tations of the external } \\
\text { world [53-55]. Perception } \\
\text { is driven by afferent senso- } \\
\text { ry information [56]. }\end{array}$} & \multirow{3}{*}{$\begin{array}{l}\text { - Perceiving external rep- } \\
\text { resentations. } \\
\text { - Analysing and interpret- } \\
\text { ing afferent visual in- } \\
\text { formation. }\end{array}$} & $\begin{array}{l}\text { Data input operator } \\
\text { [22] (V1). }\end{array}$ \\
\hline & & $\begin{array}{l}\text { Unexpected discovery } \\
\text { of visuo-spatial fea- } \\
\text { tures and relations } \\
{[28](\mathrm{V} 2) \text {. }}\end{array}$ \\
\hline & & $\begin{array}{l}\text { Information gathering } \\
{[40,57](\mathrm{V} 2) \text {. }}\end{array}$ \\
\hline \multirow{3}{*}{$\begin{array}{l}\text { Mental imagery, i.e. the } \\
\text { generation, maintenance, } \\
\text { and manipulation of inter- } \\
\text { nal images, driven by in- } \\
\text { ternal information from } \\
\text { memory but may be influ- } \\
\text { enced by incoming sensory } \\
\text { information [58]. }\end{array}$} & \multirow{3}{*}{$\begin{array}{l}\text { - Generation of mental } \\
\text { images. } \\
\text { - Maintenance of mental } \\
\text { images. } \\
\text { - Transformation of men- } \\
\text { tal images. }\end{array}$} & $\begin{array}{l}\text { Generation of mental } \\
\text { images }[3,30] \text { (V2). }\end{array}$ \\
\hline & & $\begin{array}{l}\text { Maintenance of imag- } \\
\text { es }[3,30](\mathrm{V} 2 \& 3) \text {. }\end{array}$ \\
\hline & & $\begin{array}{l}\text { Transformation of im- } \\
\text { ages }[3,30](\mathrm{V} 2 \& 3) \text {. }\end{array}$ \\
\hline \multirow{3}{*}{$\begin{array}{l}\text { Semantic association, i.e. } \\
\text { the formation of mental re- } \\
\text { lationships between mean- } \\
\text { ingful representations [59]. } \\
\text { Semantic association is in- } \\
\text { tricately related to seman- } \\
\text { tic memory (above), where } \\
\text { associations exist [60]. }\end{array}$} & \multirow[t]{3}{*}{$\begin{array}{l}\text { - Association of concepts. } \\
\text { - Transformation of con- } \\
\text { cepts. }\end{array}$} & $\begin{array}{l}\text { Generalisation opera- } \\
\text { tor - associate attrib- } \\
\text { ute to supra-symbol } \\
{[20] \text { (V1). }}\end{array}$ \\
\hline & & $\begin{array}{l}\text { Explore interactions } \\
\text { between artefacts and } \\
\text { people/nature [31] } \\
\text { (V2). }\end{array}$ \\
\hline & & $\begin{array}{l}\text { Transformation of } \\
\text { concepts [61] (V3). }\end{array}$ \\
\hline $\begin{array}{l}\text { Long term memory, sup- } \\
\text { porting long term retention } \\
\text { and retrieval of contextual- }\end{array}$ & $\begin{array}{l}\text { - Retrieval of information } \\
\text { from long term memory. }\end{array}$ & $\begin{array}{l}\text { Retrieve schema from } \\
\text { memory }[22,23,25] \\
\text { (V1). }\end{array}$ \\
\hline
\end{tabular}




\begin{tabular}{|c|c|c|}
\hline \multirow{2}{*}{$\begin{array}{l}\text { ised events (episodic } \\
\text { memory) and conceptual } \\
\text { knowledge (semantic } \\
\text { memory) }[62,63] \text {. }\end{array}$} & & $\begin{array}{l}\text { Retrieve knowledge } \\
\text { [31] (V2). }\end{array}$ \\
\hline & & $\begin{array}{l}\text { Memory retrieval [3] } \\
\text { (V3). }\end{array}$ \\
\hline $\begin{array}{l}\text { Working memory, sup- } \\
\text { porting simultaneous stor- } \\
\text { age and manipulation of } \\
\text { visuo-spatial and phono- } \\
\text { logical information } \\
{[64,65] \text {. }}\end{array}$ & $\begin{array}{l}\text { - Activation, manipula- } \\
\text { tion, and maintenance of } \\
\text { information in working } \\
\text { memory. }\end{array}$ & $\begin{array}{l}\text { Patch operator - } \\
\text { add/combine infor- } \\
\text { mation with making it } \\
\text { less abstract [23] } \\
\text { (V1). }\end{array}$ \\
\hline \multirow{2}{*}{$\begin{array}{l}\text { Selective attention, i.e. the } \\
\text { process of selecting and } \\
\text { focusing on a stimulus } \\
\text { while disregarding other } \\
\text { stimuli }[55,56] \text {. }\end{array}$} & \multirow{2}{*}{$\begin{array}{l}\text { - Focusing attention on } \\
\text { different parts of exter- } \\
\text { nal representations. } \\
\text { - Focusing attention on } \\
\text { different properties of } \\
\text { external representations. }\end{array}$} & $\begin{array}{l}\text { Select information op- } \\
\text { erator [23] (V1). }\end{array}$ \\
\hline & & $\begin{array}{l}\text { Attend to visual fea- } \\
\text { tures and spatial rela- } \\
\text { tions [31] (V2). }\end{array}$ \\
\hline \multirow{3}{*}{$\begin{array}{l}\text { Creative thinking, i.e. the } \\
\text { generative and exploratory } \\
\text { processes involved in de- } \\
\text { veloping ideas that are } \\
\text { both novel and useful } \\
\text { and/or valuable }[56,66] \text {. }\end{array}$} & \multirow[t]{3}{*}{$\begin{array}{l}\text { - Idea generation. } \\
\text { - Concept composi- } \\
\text { tion/synthesis. } \\
\text { - Concept development. }\end{array}$} & $\begin{array}{l}\text { Create operator - gen- } \\
\text { eration of information } \\
\text { that appears spontane- } \\
\text { ously [20] (V1). }\end{array}$ \\
\hline & & Imagining [30] (V2). \\
\hline & & $\begin{array}{l}\text { Concept generation } \\
\text { and composition [27] } \\
\text { (V3). }\end{array}$ \\
\hline \multirow{3}{*}{$\begin{array}{l}\text { Evaluation and decision } \\
\text { making, where decision } \\
\text { making is the deliberate } \\
\text { selection of one option } \\
\text { over another [55], and } \\
\text { evaluation is the related } \\
\text { process of determining the } \\
\text { worth or value of a par- } \\
\text { ticular outcome/entity } \\
\text { [67]. }\end{array}$} & \multirow{3}{*}{$\begin{array}{l}\text { - Comparing and judging } \\
\text { concepts. } \\
\text { - Decision making about } \\
\text { concepts. } \\
\text { - Evaluation of mental } \\
\text { images, design require- } \\
\text { ments, and design solu- } \\
\text { tions }\end{array}$} & $\begin{array}{l}\text { Reject operator - de- } \\
\text { termine unsatisfactory } \\
\text { proposal [23] (V1). }\end{array}$ \\
\hline & & $\begin{array}{l}\text { Evaluation and con- } \\
\text { firmation of internal } \\
\text { representation [30], } \\
\text { and evaluation of re- } \\
\text { quirements and solu- } \\
\text { tions [26] (V2). }\end{array}$ \\
\hline & & $\begin{array}{l}\text { Comparing and judg- } \\
\text { ing [4] (V3). }\end{array}$ \\
\hline \multirow{2}{*}{$\begin{array}{l}\text { Externalisation, referring } \\
\text { to the process of externally } \\
\text { representing an internal } \\
\text { idea or image, e.g. through } \\
\text { sketching }[24,68] \text {. }\end{array}$} & \multirow[t]{2}{*}{$\begin{array}{l}\text { - Drawing/sketching. } \\
\text { - Depicting. }\end{array}$} & $\begin{array}{l}\text { Representation opera- } \\
\text { tor - create an exter- } \\
\text { nal representation [20] } \\
\text { (V1). }\end{array}$ \\
\hline & & Drawing [30] (V2). \\
\hline \multirow[t]{2}{*}{$\begin{array}{l}\text { Reasoning and problem } \\
\text { solving, where reasoning is } \\
\text { the process of thinking in } \\
\text { accordance with logic [55], } \\
\text { and problem solving is the }\end{array}$} & \multirow[t]{2}{*}{$\begin{array}{l}\text { - Inference. } \\
\text { - Problem structuring, } \\
\text { analysis, and redefini- } \\
\text { tion. }\end{array}$} & $\begin{array}{l}\text { Search process } \\
{[2,20,22] \text { and deduc- }} \\
\text { tive reasoning }[42] \\
(\mathrm{V} 1) \text {. }\end{array}$ \\
\hline & & Invention of new de- \\
\hline
\end{tabular}




\begin{tabular}{|c|c|c|}
\hline \multirow{2}{*}{$\begin{array}{l}\text { process of finding solu- } \\
\text { tions to problems [24]. A } \\
\text { problem is a situation } \\
\text { where the end goal is } \\
\text { known, but the means of } \\
\text { achieving it are not } \\
{[24,55] \text {. }}\end{array}$} & \multirow{2}{*}{$\begin{array}{l}\text { - Solution search. } \\
\text { - Process control (e.g. } \\
\text { monitoring and manag- } \\
\text { ing goals, constraints, } \\
\text { and requirements). }\end{array}$} & $\begin{array}{l}\text { sign requirements [28] } \\
\text { (V2). }\end{array}$ \\
\hline & & $\begin{array}{l}\text { Problem analysis [27] } \\
\text { (V3). }\end{array}$ \\
\hline
\end{tabular}

\section{Key observations and future work}

Whilst the variation in concepts and terminology may be attributed to differences in underlying paradigms, it also highlights a lack of general models and theories of conceptual design cognition. This conclusion is supported to some extent by Dinar et al. [7], who argue that the field suffers from a lack of "cognitive models and theories of designer thinking." Models and theories may be applied to generate predictions about different aspects of cognition, which may then be tested experimentally to further our knowledge of designers' internal processing. Thus, they are crucial for advancing the field (p.9).

Developing general formalisms to describe the cognitive processing involved in conceptual design requires an understanding of: (i) the cognitive processes fundamentally involved; and (ii) the interactions between the processes. The review reported herein has consolidated knowledge relating to (i), outlining a range of executive and non-executive functions studied across different viewpoints and domains. With respect to (ii), a number of authors in the sample were found to propose tentative relationships and cognitive models on the basis of protocol analysis findings e.g. $[3,28,30,69,70]$. However, a weakness associated with knowledge derived from protocol studies is that it is necessarily based on small samples of designers, and subjective inference from verbal and behavioural data. Subjectivity is particularly problematic in the study of non-executive functions, which are typically not accessible to consciousness for verbal reporting [51] and therefore tend to be inferred from observations of physical behaviour alone (e.g. mental imagery processing in [30]). Although the use of standard coding schemes and multiple coders can reduce subjectivity to some extent, these do not address issues relating to sample size, e.g. the statistical significance and generalisability of results. Thus, a significant avenue for future research is testing the findings and hypotheses generated through protocol studies using more objective methods conducive to the study of larger samples. Dinar et al. [7] highlight the use of controlled lab experiments, typical of cognitive psychology research, as a potential approach in this respect. Systematically reviewing the relatively small number of these studies conducted to date presents another task for future re- 
search. A more fundamental challenge for the field as it advances may be how to integrate rich, qualitative approaches such as protocol analysis with more objective and extensive quantitative approaches.

Finally, the variation in concepts and terminology exposed by the review also points to a fundamental question for research on conceptual design cognition: what processes and relationships are actually of interest, and how should they be defined for study? Whilst the function categories applied in this review are reasonable from a psychology perspective, they may not constitute the most appropriate means of defining and organising the processes involved in design. This may be seen to mirror current ontological debates in psychology and neuroscience research, where efforts are under way to develop a shared ontology of processes and relationships [71]. Several design researchers have proposed ontologies, e.g. $[15,38,72]$. However, these tend to neglect non-executive functions and are not necessarily intended to describe design at the cognitive level. The development of a general ontology of cognitive processes in conceptual design would not only provide a consistent and comprehensive basis for developing theories and models, but it would also increase the comparability of findings from different studies and promote a more integrated body of knowledge on design cognition.

\section{Concluding remarks}

This paper has reported the findings of the first systematic review of protocol studies specifically focusing on conceptual design cognition. Current knowledge regarding the nature of the cognitive processes involved in conceptual design tasks has been consolidated, revealing ten categories of executive and non-executive function that appear to be studied across the field. The findings highlight several avenues for future research, centering on the need for general formalisms, more objective methods to supplement protocol analysis, and a shared ontology of cognitive processes in conceptual design.

In closing, the work has demonstrated that the systematic review method provides a means to synthesise the findings of a large number of studies in a rigorous and transparent manner, revealing common findings and exposing differences in perspectives and terminology. Thus, further use of the method may help to build a more integrated body of knowledge on design cognition, and therefore make a significant contribution to advancing the cognitive component of design science. 


\section{References}

References marked with * are included in the systematic review sample.

1. *McNeill T, Gero JS, Warren J (1998) Understanding conceptual electronic design using protocol analysis. Res Eng Des 10(3):129-140

2. *Goel V (1995) Sketches of thought. MIT Press: Cambridge, Mass.

3. *Jin Y, Benami O (2010) Creative patterns and stimulation in conceptual design. Artif Intell Eng Des Anal Manuf 24(02):191-209

4. *Kim J, Ryu H (2014) A Design Thinking Rationality Framework: Framing and Solving Design Problems in Early Concept Generation. HumanComputer Interact 29(5-6):516-553

5. *Dorst K, Cross N (2001) Creativity in the design process: co-evolution of problem-solution. Des Stud 22(5):425-437

6. Cross N (2001) Design Cognition: Results From Protocol And Other Empirical Studies Of Design Activity. In: Eastman CM, McCracken WM, Newstetter WC, editors. Design Knowing and Learning: Cognition in Design Education. Elsevier Science Ltd: Oxford

7. Dinar M, Shah JJ, Cagan J, Leifer L, Linsey J, Smith SM, et al. (2015) Empirical Studies of Designer Thinking: Past, Present, and Future. J Mech Des 137(2):1-13

8. Jiang H, Yen C-C (2009) Protocol Analysis in Design Research: A review. Rigor and Relevance in Design: IASDR 2009, Seoul, Korea October 18-22. pp.147-156

9. Moher D, Liberati A, Tetzlaff J, Altman DG (2009) Preferred reporting items for systematic reviews and meta-analyses: the PRISMA statement. PLoS Med 6(7):1-6

10. Lloyd P, Lawson B, Scott P (1995) Can concurrent verbalization reveal design cognition? Des Stud 16(2):237-59

11. Hubka V (1982) Principles of Engineering Design. Butterworth \& Co (Publishers) Ltd: London, Boston

12. Roozenburg NFM, Eekels J (1994) Product design: fundamentals and methods. Wiley: Chichester, New York.

13. Kim KM, Lee KP (2010) Two types of design approaches regarding industrial design and engineering design in product design. DESIGN 2010 11th International Design Conference. pp.1795-806

14. Akin Ö (1986) Psychology of Architectural Design. Pion: London

15. Gero JS (1990) Design Prototypes: A Knowledge Representation Schema for Design. AI Mag 11(4):26-36

16. Dorst K, Dijkhuis J (1995) Comparing paradigms for describing design activity. Des Stud 16(2):261-74

17. Suwa M, Tversky B (1996) What architects see in their sketches: implications for design tools. In Conference Companion on Human Factors in Computing Systems: Common Ground. pp.191-192

18. Suwa M, Gero JS, Purcell T (1998) Analysis of cognitive processes of a 
designer as the foundation for support tools. Artif Intell Des 98:229-248

19. Suwa M, Tversky B, Gero J, Purcell T (1994) Seeing into sketches: regrouping parts encourages new interpretations. Visual and Spatial Reasoning in Design II. pp.207-219

20. *Akin Ö (1984) An Exploration of the Design Process. In: Cross N, editor. Developments in Design Methodology. John Wiley \& Sons Ltd.: Chichester, New York, Brisbane, Toronto, Singapore. pp.189-207

21. *Yu R, Gero JS (2015) An empirical foundation for design patterns in parametric design. In: Ikeda Y, Herr CM, Holzer D, Kaijima S, Kim MJ, Schnabel A, editors. Proceedings of the 20th International Conference of the Association for Computer-Aided Architectural Design Research in Asia CAADRIA. pp. 1-9

22. *Chan C-S (1990) Cognitive processes in architectural problem solving. Des Stud 11(2):60-80

23. *Stauffer LA, Ullman DG (1991) Fundamental Processes of Mechanical Designers Based on Empirical Data. J Eng Des 2(2):113-125

24. Newell A, Simon HA (1972) Human problem solving. Prentice-Hall: Englewood Cliffs, New Jersey.

25. *Ball LJ, Ormerod TC, Morley NJ (2004) Spontaneous analogising in engineering design: A comparative analysis of experts and novices. Des Stud 25(5):495-508

26. *Maher M, Tang H-H (2003) Co-evolution as a computational and cognitive model of design. Res Eng Des 14(1):47-64

27. *Jin Y, Chusilp P (2006) Study of mental iteration in different design situations. Des Stud 27(1):25-55

28. *Suwa M, Gero J, Purcell T (2000) Unexpected discoveries and S-invention of design requirements: important vehicles for a design process. Des Stud 21(2000):539-567

29. *Goldschmidt G (1991) The dialectics of sketching. Creat Res J 4(2):123143

30. *Park J, Kim Y (2007) Visual reasoning and design processes. International Conference on Engineering Design, ICED'07. pp.1-12.

31. *Suwa M, Purcell T, Gero J (1998) Macroscopic analysis of design processes based on a scheme for coding designers' cognitive actions. Des Stud 19(4):455-483

32. *Suwa M, Tversky B (1997) What do architects and students perceive in their design sketches? A protocol analysis. Des Stud 18(4):385-403.

33. *Athavankar UA (1997) Mental Imagery As a Design Tool. Cybern Syst 28(1):25-42

34. *Bilda Z, Gero JS, Purcell T (2006) To sketch or not to sketch? That is the question. Des Stud 27(5):587-613

35. *Bilda Z, Gero JS (2007) The impact of working memory limitations on the design process during conceptualization. Des Stud 28(4):343-367

36. *Athavankar U, Bokil P, Guruprasad K (2008) Reaching out in the mind's space. Design Computing and Cognition '08. Springer Netherlands. p. 321340 
37. Hubka V, Eder WE (1996) Design science: introduction to needs, scope and organization of engineering design knowledge. Springer: Berlin, New York

38. Sim SK, Duffy AHB (2003) Towards an ontology of generic engineering design activities. Res Eng Des 14(4):200-223

39. *Liikkanen LA, Perttula M (2009) Exploring problem decomposition in conceptual design among novice designers. Des Stud 30(1):38-59

40. *Kim Y, Jin S, Lee H (2005) Dual protocol analysis based on design information and design process : A case study. Studying Designers '05, Aixen-Provence, France. Key Centre of Design Computing and Cognition. pp.71-85.

41. *Eckersley M (1998) The form of design processes: a protocol analysis study. Des Stud 9(2):86-94.

42. *Lloyd P, Scott P (1994) Discovering the design problem. Des Stud 15(2):125-140

43. *Lee J, Gu N, Williams A (2014) Parametric Design Strategies for the Generation of Creative Designs. Int J Archit Comput 12(3):263-282

44. *Lane D, Seery N (2011) Examining the development of sketch thinking and behaviour. Annual Conference for the American Society of Engineering Education, Vancouver, Canada

45. *Daly SR, Yilmaz S, Christian JL, Seifert CM, Gonzalez R (2012) Design Heuristics in Engineering. J Eng Educ 101(4):601-629

46. *Akin O, Akin C (1996) Frames of reference in architectural design: analysing the hyperacclamation (a-h-a-!). Des Stud 17(4):341-361

47. *Kruger C, Cross N (2006) Solution driven versus problem driven design: strategies and outcomes. Des Stud 27(5):527-548

48. *Chiu ML (2003) Design moves in situated design with case-based reasoning. Des Stud 24(1):1-25.

49. *Chandrasekera T, Vo N, D'Souza N (2013) The effect of subliminal suggestions on Sudden Moments of Inspiration (SMI) in the design process. Des Stud 34(2):193-215

50. Schön DA (1983) The reflective practitioner: how professionals think in action. Basic Books: Pennsylvania

51. Rabbitt P (2004) Methodology of frontal and executive function. Psychology Press Ltd: online.

52. Chan RCK, Shum D, Toulopoulou T, Chen EYH (2008) Assessment of executive functions: review of instruments and identification of critical issues. Arch Clin Neuropsychol 23(2):201-16

53. Bruce V, Green PR, Georgeson MA (2003) Visual perception: physiology, psychology and ecology. Psychology Press: New York

54. Milner AD, Goodale MA (2008) Two visual systems re-viewed. Neuropsychologia 46(3):774-85

55. Gobet F, Chassy P, Bilalic M (2011) Foundations of Cognitive Psychology. McGraw-Hill Education: Maidenhead

56. Eysenck MW, Keane MT (2005) Cognitive Psychology: A Student's Handbook. 5th ed. Pyschology Press Ltd.: Hove

57. *Kim YS, Jin ST, Lee SW (2006) Design activities and personal creativity 
characteristics: A case study of dual protocol analysis using design information and process. ASME 2006 International Design Engineering Technical Conferences and Computers and Information in Engineering Conference, Philadelphia.

58. Kosslyn SM (1995) Mental imagery. In: Kosslyn SM, Osherson DN, editors. Visual cognition: An invitation to cognitive science, Vol 2. p. 267-296.

59. Federmeier KD, McLennan DB, Ochoa E, Kutas M (2002) The impact of semantic memory organization and sentence context information on spoken language processing by younger and older adults: An ERP study. Psychophysiology 39(2):133-46

60. Martin A, Chao LL (2001) Semantic memory and the brain: structure and processes. Curr Opin Neurobiol 11(2):194-201

61. *Leblebici-Basar D, Altarriba J (2013) The Role of Imagery and Emotion in the Translation of Concepts into Product Form. Des J 16(3):295-314

62. Tulving E (1983) Elements of episodic memory. Clarendon Press: Oxford

63. Squire LR, Zola SM (1998) Episodic Memory, Semantic Memory, and Amnesia. Hippocampus 8:205-211

64. Baddeley A (1983) Working memory. Philos Trans R Soc Lond B Biol Sci 302(1110):311-324

65. Baddeley A (2003) Working memory: looking back and looking forward. Nat Rev - Neurosci 4:829-839

66. Finke RA (1996) Imagery, creativity, and emergent structure. Conscious Cogn 5(3):381-93

67. Gawronski B, Bodenhausen G (2006) Associative and Propositional Processes in Evaluation: An Integrative Review of Implicit and Explicit Attitude Change. Psychological Bulletin 132(5):692-731

68. Fish J, Scrivener S (1990) Amplifying the Mind's Eye: Sketching and Visual Cognition. Leonardo 23(1):117-126

69. *Kavakli M, Gero JS (2002) The structure of concurrent cognitive actions: A case study on novice and expert designers. Des Stud 23(1):25-40

70. *Kim JE, Bouchard C, Omhover JF, Aoussat A (2010) Towards a model of how designers mentally categorise design information. CIRP J Manuf Sci Technol 3(3):218-26

71. Poldrack RA, Kittur A, Kalar D, Miller E, Seppa C, Gil Y, et al. (2011) The cognitive atlas: toward a knowledge foundation for cognitive neuroscience. Front Neuroinform 5:1-11

72. Gero JS, Kannengiesser U (2004) A function-behavior-structure ontology of processes. AI EDAM 21(04):379-391 